\title{
ACUTE AIRWAY OBSTRUCTION: A COMPLICATION OF ALUMINUM TAPE WRAPPING OF TRACHEAL TUBES IN LASER SURGERY
}

\author{
Collin S. Kaeder and Carol A. Hirshiman
}

SinCE its introduction in the early seventies the use of the carbon dioxide laser for laryngeal surgery has been increasing.

If the tracheal tube is situated near the operative site, ignition of the tube may occur, produc. ing airway burns. Wrapping of the tracheal tube with aluminum tape prevents ignition of the tube by the laser beam but may itself introduce other complications.

We are reporting a case of acute airway obstruction arising from the use of aluminum tape wrapping on the tracheal tube during laryngeal surgery with a carbon dioxide laser.

\section{REPORT OF A CASE}

T.J. is a 12-year-old male with a tracheostomy who was scheduled for his $100 \mathrm{th}$ anaesthetic for resection of laryngeal and tracheal papillomata. The previous 99 operations were done without the laser. On this occasion the child was brought to the operating room without premedication. Anaesthesia was induced with halothane, oxygen and nitrous oxide through his tracheostomy tube. The tracheostomy tube was replaced with a $6 \mathrm{~mm}$ uncuffed Portex tracheal tube spiral wrapped with aluminum tape in order to decrease the leak and to allow better ventilation of the patient.

After laser cautery of the laryngeal polyps was completed, a bronchoscope was passed orally and advanced into the trachea. Many papillomata were seen in the trachea and surgical excision of these through the tracheostomy was planned.

Immediately following the bronchoscopy, the patient became increasingly difficult to ventilate. The nitrous oxide was discontinued. Multifocal ventricular beats appeared on the electrocardiogram and the patient became mildly cyanotic. The tracheal tube was removed and replaced with an unwrapped tube of similar size.

Collin S. Kaeder, M.D., Resident, Carol A. Hirshman, M.D., Assistant Professor, Department of Anesthesiology, University of Oregon Health Sciences Center, Portland, Oregon, U.S.A.

Correspondence to: Carol A. Hirshman, M.D., Department of Anesthesiology, University of Oregon Health Sciences Center, 3181 S. W. Sam Jackson Park Road, Portland, Oregon 97201, U.S.A.

Canad. Anaesth. Soc. J., vol. 26,-no. 2, March 1979
Ventilation was still very difficult. Inspection of the tracheal tube removed from the patient revealed several areas where the tape was now missing. The pieces of tape were removed from the trachea under direct vision using a small laryngoscope inserted into the tracheal stoma. The patient immediately became easier to ventilate. The electrocardiogram reverted to sinus rhythm. Anaesthesia was maintained by intermittent use of 98 per cent $0 x y$ gen and two per cent halothane through an untaped tracheal tube. Resection of the remaining paillomata proceeded uneventfully without the laser. The patient awakened without incident. Chest $\mathrm{X}$-ray revealed no foreign body in the airway. He was discharged the following day.

\section{Discussion}

The use of lasers in the operating room is new in many centers. The technical aspects of dealing with this surgical advance are also in the developing stage. Birch, in 1973, discussed the medical uses and complications of lasers.' Snow, et al. reported on the use of laser microsurgery on the laryn $x$ and trachea. ${ }^{2}$ One major complication of laser surgery is ignition of anaesthesic equipment, particularly plastic tracheal tubes, producing airway burns. ${ }^{3}$ The only available technique that we know to prevent this complication is to wrap the tracheal tube with reflective tape. This tape has some significant drawbacks. The tape does not adhere well to the tube and pieces of tape can easily be torn off, as happened in our case. We routinely apply the tape in one piece in a spiral around the tube. This creates a rough surface which could conceivably damage airway mucosa. In our experience longitudinal application of the tape results in kinking of the tube and obstruction of the airway in every case. Metal impregnated tracheal tubes are not to our knowledge available. It is possible to avoid tracheal intubation entirely by using a ventilating laryngoscope ${ }^{4}$ or by giving anaesthesia by insufflation. If the patient has a metal tracheostomy tube in place it is preferable to use that, 38 
If it becomes necessary to use a tracheal tube wrapped with aluminum tape the precautions to be taken are meticulous spiral wrapping with no protruding edges, minimum deformation of tube and careful inspection of the tube after withdrawal.

\section{SUMMARY}

A case is reported of acute airway obstruction arising from the use of a tracheal tube wrapped with aluminum tape during laryngeal surgery with a carbon dioxide laser. Problems associated with aluminum tape wrapping of tracheal tubes are discussed.

\section{RÉSUMÉ}

Les auteurs rapportent un cas d'obstruction des voies respiratoires causée par l'emploi d'une sonde endotrachéale recouverte d'un ruban adhésif d'aluminium pendant une opération effectuée sous laser au gaz carbonique. Ils discutent des problèmes causés par le recouvrement des sondes endotrachéales par du ruban adhésif d'aluminium.

\section{REFERENCES}

1. Birch, A.A. Anesthetic considerations during laser surgery. Anesth. Analg. 52:53-58, 1973.

2. Snow, J.C. Kripke, B.J., Strong, M.S., JAKo, G.J., MeYer, M.R., \& Vaughan, C.W. Anesthesia for carbon dioxide laser microsurgery on the larynx and trachea. Anesth. Analg. 53: 507-512, 1974.

3. Snow, J.C., Norton, M.L., Saluja, T.S., \& EsTANISLAO, A.E. Fire hazard during $\mathrm{CO}_{2}$ laser microsurgery on the larynx and trachea. Anesth. Analg. 55: 146-147, 1976.

4. Oulton, J.L. \& Donald, D.M. A ventilating laryngoscope. Anesthesiology 35: 540-542, 1971. 